\title{
Correction to: Malignant struma ovarii: next-generation sequencing of six cases revealed Nras, Braf, and Jak3 mutations
}

\author{
Roberta Poli $\mathbb{D}^{1}$ - Maria Scatolini $\mathbb{D}^{2}$ - Enrico Grosso ${ }^{2}$ - Francesca Maletta ${ }^{3}$ - Marco Gallo ${ }^{4}$ Daniele Liscia ${ }^{5}$. \\ Anna Nelva ${ }^{6} \cdot$ Flora Cesario $^{7} \cdot$ Giuseppe Forte $^{8} \cdot$ Jasna Metovic $^{9} \cdot$ Marco Volante $^{9} \cdot$ Emanuela Arvat $^{10}$. \\ Mauro Papotti ${ }^{9}$
}

Published online: 6 October 2020

(c) Springer Science+Business Media, LLC, part of Springer Nature 2020

Correction to: Endocrine
\[ \begin{array}{l}\text { https://doi.org/10.1007/s12020-020-02438-7 } \\ \text { published online } 02 \text { August 2020 }\end{array} \]

The original version of this article published online in SpringerLink contained an error in author names. The given and family names of all the authors were interchanged. The author names are corrected with this correction.

The original article has been corrected.

The original article can be found online at https://doi.org/10.1007/ s12020-020-02438-7.

$\triangle$ Roberta Poli

rob.poli1979@libero.it

1 Division of Internal Medicine, Ospedale degli Infermi, via dei Ponderanesi 2 Ponderano, 13875 Biella, Italy

2 Molecular Oncology Laboratory, Fondazione "Edo ed Elvo Tempia Valenta", via dei Ponderanesi 2, Ponderano, 13875 Biella, Italy

3 Pathology Unit, AOU Città della Salute e della Scienza Hospital, via Santena 7, 10126 Turin, Italy

4 Oncological Endocrinology, AOU Città della Salute e della Scienza di Torino Hospital, via Genova 3, 10126 Turin, Italy

5 Pathology Unit, Ospedale degli Infermi, via dei Ponderanesi 2 Ponderano, 13875 Biella, Italy
6 Endocrinology and Diabetology Unit, Ospedale degli Infermi, via dei Ponderanesi 2 Ponderano, 13875 Biella, Italy

7 Division of Endocrinology, Diabetes and Metabolism, Santa Croce e Carle Hospital, Cuneo, Italy

8 Pathology Unit, Santa Croce e Carle Hospital, via M Coppino 26, 12100 Cuneo, Italy

9 Pathology Unit, Department of Oncology, University of Turin, via Santena 7, 10126 Turin, Italy

10 Oncological Endocrinology, Department of Medical Sciences, University of Turin, via Genova 3, 10126 Turin, Italy 